\title{
Analisis Implementasi Pembelajaran Aljabar pada Anak Usia 5-6 Tahun
}

\author{
Febru Puji Astuti ${ }^{1}$, Reza Edwin Sulistyaningtyas ${ }^{2}{ }^{\bowtie}$, Firdha Faradhita Yogi Fardani ${ }^{3}$, Melati \\ Ariana ${ }^{4}$, Chomisah Nugraheni ${ }^{5}$ \\ Pendidikan Guru Pendidikan Anak Usia Dini, Universitas Muhammadiyah Magelang, \\ Indonesia ${ }^{(1)}$
}

DOI: $10.31004 /$ obsesi.v6i3.1682

\begin{abstract}
Abstrak
Matematika merupakan salah satu fondasi penting dalam perkembangan kemampuan akademik anak. Pembelajaran matematika pada anak tidak hanya berpusat pada angka namun lebih kepada bagaimana membangun pola berfikir anak melalui aktivitas-aktivitas yang memungkinkan anak terpapar pada ide-ide matematika baik secara sederhana maupun komplek. Penelitian ini bertujuan untuk mengetahui pengimplementasian kegiatan pembelajaran aljabar pada tingkat TK B. Penelitian ini menggunakan jenis penelitian survei dengan menggunakan angket sebagai alat pengumpul data. Angket digunakan untuk mendapatkan data berkaitan dengan konteks materi aljabar yang diajarkan oleh guru. Berdasarkan hasil penelitian yang dilakukan diperoleh data sebagai berikut: implementasi aljabar pada tingkat TK di kabupaten Magelang dikategorikan cukup, materi Aljabar belum semua dikuasai dan diimplementasikan oleh guru, dan faktor penghambat implementasi materi aljabar diantaranya faktor waktu yang terbatas dalam kegiatan belajar dan minimnya buku panduan materi aljabar pada TK. Dengan demikian, materi pembelajaran aljabar perlu lebih dipahami dan dikuasi oleh guru agar pembelajaran dapat lebih maksimal.
\end{abstract}

Kata Kunci: Pendidikan Anak Usia Dini; Aljabar AUD; Pembelajaran matematika.

\begin{abstract}
Mathematics is one of the important foundations in the development of children's academic abilities. Learning mathematics in children is not only centered on numbers but rather on how to build children's thinking patterns through activities that allow children to be exposed to mathematical ideas, both simple and complex. This study aims to determine the implementation of algebra learning activities at the Kindergarten B level. This study uses a survey research type using a questionnaire as a data collection tool. Questionnaires were used to obtain data related to the context of the algebraic material taught by the teacher. Based on the results of the research conducted, the following data were obtained: the implementation of algebra at the kindergarten level in Magelang district was categorized as sufficient, not all Algebra materials were mastered and implemented by teachers, and the inhibiting factors for the implementation of algebraic materials included the limited time factor in learning activities and the lack of material guide books. algebra in kindergarten. Thus, algebra learning materials need to be better understood and mastered by teachers so that learning can be maximized.
\end{abstract}

Keywords: Early Childhood Education Programs; early Childhood Algebra; Mathematics Learning.

Copyright (c) 2021 Febru Puji Astuti, et al.

$\triangle$ Corresponding author:

Email Address : reza.edwin@ummgl.ac.id (Magelang, Jawa Tengah, Indonesia)

Received tanggal bulan tahun, Accepted tanggal bulan tahun, Published tanggal bulan tahun 


\section{PENDAHULUAN}

Pendidikan saat ini berada pada titik di mana dalam prosesnya tidak hanya dituntut agar kreatif namun juga inovatif. Hal ini, dikarenakan kita telah memasuki perkembangan dunia abad 21 dengan pemanfaatan teknologi yang semakin pesat dalam segara aspek kehidupan. Lembaga pendidikan dituntut untuk dapat mengikuti perkembangan yang ada dengan menyediakan sarana dan prasarana yang menunjang. Keberhasilan program pendidikan sekolah sangat dipengaruhi oleh kondisi dan optimalisasi sarana dan prasarana yang dimiliki sekolah (Matin \& Fuad, 2016).

Kemampuan dan kompetensi peserta didik pun berkembang dan memiliki tuntutan yang semakin meningkat seiring dengan perkembangan teknologi dan informasi yang ada. Peningkatan kompetensi anak tidak hanya terjadi pada jenjang sekolah tinggi namun hal ini dimulai sejak anak berada pada jenjang terendah dalam hal ini PAUD. Secara akademik anak usia dini mengalami tuntutan yang berkembang dalam hal akademik utamanya dalam konteks akademik. Salah satu kemampuan yang penting untuk dikuasai anak usia dini adalah matematika. Matematika sebagai bagian kompetensi akademik yang perlu diajarkan dan dikuasasi oleh anak menjadi salah satu pusat perhatian bagi guru dalam pengembangannya. Kemampuan matematika sangat penting bagi kehidupan sehingga harus dimiliki oleh setiap orang. Sayangnya, kemampuan matematika pada anak di Indonesia berdasarkan hasil PISA (Programme for International Student Assessment) pada tahun 2018 menurun jika dibandingkan pada tahun 2015. Data PISA menunjukkan pada tahun 2015 Indonesia berada pada rangking 64 dari 72 negara dengan skor matematika 386 sedangkan di tahun 2018 Indonesia berada pada peringkat 74 dari 79 negara dengan skor matematika 379 (Tohir, 2019).

Pembelajaran matematika merupakan salah satu materi pembelajaran yang dianggap cukup sulit diajarkan dalam setiap jenjang pendidikan. Pada jenjang anak usia dini utamanya dikarenakan matematika dianggap sebagai materi yang abstrak bagi anak sehingga perlu dihindari (Rutunkahu \& Kandou, 2017). Penelitian menunjukkan bahwa anak mampu mengembangkan konsep dan melakukan proses matematika secara alami (J. Sarama \& Clements, 2010). Hal ini didukung dengan penelitian-penelitian selanjutnya yang berfokus pada penalaran aljabar awal (Papic et al., 2011) probalitas dan penalaran statistik sederhana pada anak (English, 2012). Selain itu temuan lain menyebutkan bahwa terdapat indikasi anak usia dini telah memiliki kemampuan untuk berfikir aljabar awal (Rusdiana \& Sudirman, 2016). Aljabar sebagai salah satu bagian dari matematika berperan sebagai pondasi dari semua bidang Proposal Penelitian 6 matematika, hal ini dikarenakan aljabar mencakup kemampuan menganalisis, memecahkan masalah, dan menyatakan serta membuktikan generalisasi. Namun, masih banyak guru yang kurang fokus dan berpendapat bahwa anak-anak tidak perlu diajarkan konsep aljabar karena dianggap terlalu abstrak bagi anak, hal ini tentunya akan merugikan dalam memaknai arti di balik symbol, keterkaitan serta alogaritma dengan rumus pada pendidikan selanjutnya (Gardiner et al., 2011).

Pembelajaran matematika pada anak usia dini pada hakekatnya memiliki beragam kompetensi yang harus dikuasai oleh anak diantaranya pemahaman konseptual, penalaran adaptif, serta kefasihan prosedural (J. A. Sarama \& Clements, 2009; Suryani \& Haryono, 2018). Sehingga, berdasarkan penjabaran diatas dapat dipahami bahwa pembelajaran matematika khususnya aljabar kiranya perlu bagi guru dalam prakteknya harus memahami dan memiliki strategi pembelajaran yang menarik dan juga dituntut untuk menguasai cakupan materi matematika yang perlu diajarkan dan dikuasai oleh anak. Sayangnya, kompetensi guru mempengaruhi penerimaan pengetahuan anak yang akan berimbas bagi kehidupan anak kedepannya. Temuan terkait dengan pengetahuan guru dalam mengajarkan matematika membenarkan bahwa guru prasekolah membutuhkan pelatihan intensif seperti kursus yang sepenuhnya berfokus pada pengajaran matematika agar pengetahuan pengajaran matematika lebih disempurnakan dan pengajaran menjadi lebih berwawasan pengetahuan ( $\mathrm{Li}, 2020)$. 
Pengembangan kemampuan matematika yang lebih komprehensif dan abstrak secara efektif anak usia dini membutuhkan pengajaran yang disengaja untuk mendukung pengalaman belajar yang menjelaskan konsep matematika yang lebih progresif dan menyesuaikan dengan kemajuan perkembangan matematika (Rusdiana \& Sudirman, 2016). Konsep matematika pada anak berkembang dan dikembangkan melalui ragam kegiatan yang diberikan oleh guru selama proses pembelajaran. Serta melalui pengalaman, bermain, dan melakukan sendiri pada anak yang terlihat melalui kegiatan menyentuh, mencocokkan, berbagi, memasangkan, menyatukan, mengelompokkan merupakan salah satu cara anak mulai memupuk pemahaman matematika mereka yang akan berguna dalam memahami matematika pada tingkat yang lebih tinggi nantinya (Brandt, 2013; Misrawati \& Suryana, 2021; Nunes et al., 2009). Berdasarkan hasil penelitian terdahulu yang melibatkan 384 anak dari 18 kelas TK menyebutkan bahwa penerapan buku bergambar selama 3 bulan dapat meningkatkan kemampuan matematika anak dengan peningkatan skor pretest dan posttestnya 22\% lebih besar (Heuvel-Panhuizen et al., 2016). Hasil penelitian lain menyebutkan bahwa kecerdasaan logika matematika dengan menggunakan kartu angka pada subjek 20 anak meningkat setelah ada perbaikan pembelajaran melalui metode kartu angka dalam meningkatkan kecerdasaan logika matematika (Mufarizuddin, 2017).

Melalui kegiatan-kegiatan yang merangsang anak untuk berfikir, memecahkan masalah, serta memerlukan proses berfikir yang kompleks anak dilatih untuk mengembangkan kemampuan berfikir logis, konsep konkrtit ke abstrak dengan lebih mudah dipahami (Kirkland et al., 2015). Dapat disimpulkan bahwa dengan memberikan kesempatan pada anak untuk belajar tentang matematika menjadi penting agar anak memiliki pengalaman tentang memecahkan masalah matematika. Aljabar yang merupakan fondasi di semua bidang matematika menyediakan alat (yaitu, bahasa dan struktur) yang digunakan untuk mewakili dan menganalisis hubungan kuantitatif, situasi pemodelan, memecahkan masalah, dan menyatakan serta membuktikan persamaan (Ball, 2003) menjadi salah satu dasar kuat perlunya mengenalkan aljabar sejak dini pada anak. Penelitian yang dilakukan oleh Papandreou \& Tsiouli (2020) yang melibatkan 13 anak yang bermain di semua area bermain dengan mengamati pengetahuan matematika anak diperoleh data bahwa berpikir aljabar pada anak usia dini hanya sebesar 1,8\% jika dibanding dengan topik lainnya (angka dan operasi hitung, pengukuran, dan geometri). Oleh karena itu perlu memberikan kesempatan anak untuk berpikir secara aljabar mendukung anak untuk dapat berpikir rekursif (berpikir untuk menemukan pola) dan fungsional saat memecahkan masalah pola sebagai salah satu bagian dari aljabar (Afonso \& Auliffe, 2019). Matematika merupakan satu proses berfikir yang mencakup penerimaan, pengolahan, penyimpulan dan mengulang informasi, dengan kata lain matematika tidak berbatas pada menghapal rumus atau angka namun serangkaian proses berfikir untuk menghasilkan pengetahuan, pemahaman dan pemecahan masalah (Adjie et al., 2020).

Penalaran aljabar pada anak dimulai dengan kegiatan-kegiatan yang mudah dan sering dialami oleh anak, hal ini dimaksudkan agar anak lebih mudah memahami apa yang dilakukan sehingga memperoleh pengetahuan yang lebih dalam. Materi pembelajaran aljabar pada anak usia dini mencakup (Lee et al., 2016): Pertama, Mencocokkan dan menyortir, kegiatan ini memungkinkan anak belajar konsep pra-aljabar dan secara konsisten memberi anak banyak kesempatan untuk berlatih dengan benda-benda konkrit berdasarkan atribut tertentu yang akrab dan dekat dengan anak. Konsep bahasa aljabar yang dipelajari anak, sama. Berbeda, mencocokkan/menyortir. Kedua, Pola: mengidentifikasi dan membuat/mengkreasi, anak melihat dan mengalami baik pengulangan dan memperluas pemahaman polanya melalui kegiatan rutin harian. Menyediakan material yang dikenal dan tidak dikenal menungkinkaan anak untuk memahami aljabar dalam kehidupan nyata. Konsep bahasa aljabar yang dipelajari anak pola, pengulangan/mengikuti pola, pola sama, pola berbeda, perluasan pola. Ketiga, Korelasi dan fungsi antara, anak memahami konsep kesetaraan, yang menggambarkan kesamaan berat, volume, nilai dll adalah sama.konsep 
bahasa aljabar yang dipelajari diantaranya sama, berbeda, umum, lebih, kurang, total, penjumlahan dan pengurangan. Ke empat, Perubahan kualitatif dan kuantitatif, memahami perubahan kualitatif dan kuantitatif dalam situasi kehidupan nyata mendorong penalaran aljabar (Keller et al., 2001). Pemahaman ini mendorong anak untuk berfikir logis tentang suatu variable dan perubahan dalam bentuk konkret. Salah satu bentuk kegiatannya adalah pengukuran. Berdasar latar belakang dan temuan yang ada peneliti bertujuan untuk mengkaji tentang implementasi materi aljabar yang diberikan oleh guru pada kelas usia 5-6 tahun.

\section{METODOLOGI}

Metode penelitian yang digunakan adalah survei. Metode survei adalah metode sistematis untuk mengumpulkan informasi dari sampel untuk tujuan membangun deskriptor kuantitatif atribut dari populasi yang lebih besar (Groves et al., 2009). Teknik pengumpulan data yang digunakan adalah angket dan instrumennya adalah lembar angket. Lembar angket memuat pertanyaan-pertanyaan yang harus dijawab oleh responden dengan mengikuti petunjuk. Pertanyaan yang disusun terdiri dari pertanyaan terbuka dan pertanyaan dengan pilihan jawaban. Jika pertanyaan terbuka responden dapat mengisi sesuai kondisi nyata yang dialami oleh responden sedangkan pertanyaan yang sudah ada pilihan jawaban maka responden diminta untuk menjawab sesuai dengan pilihan jawaban yang ada. Pertanyaan yang diberikan terkait dengan implementasi pembelajaran aljabar pada anak usia 5-6 tahun di kabupaten Magelang yang dibagi menjadi 4 indikator diantaranya adalah Pengetahuan guru tentang pembelajaran aljabar, keterampilan guru dalam pembelajaran aljabar, motivasi guru saat mengajar dan kendala yang dihadapi. Lembar angket yang diberikan kepada responden disusun dalam bentuk angket online dengan bantuan googleform.

Subjek penelitian yang dilibatkan adalah guru yang mengajar pada tingkat taman kanak-kanak (TK) di kabupaten Magelang sebanyak 22 sekolah. Guru yang telah mengisi lembar angket yang telah disebarluaskan melalui googleform teridentifikasi sebanyak 32 orang. Teknik analisis data dengan statistik deskriptif.

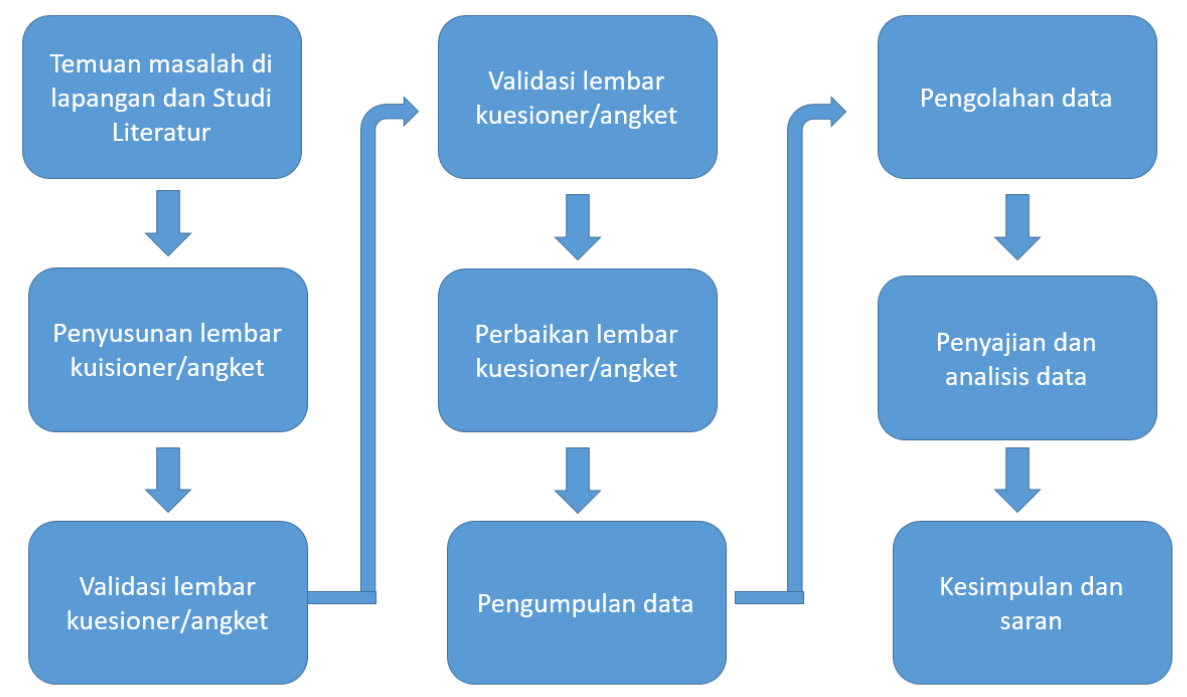

Gambar 1. Tahapan Penelitian

\section{HASIL DAN PEMBAHASAN}

Pendidikan anak usia dini sebagai bentuk upaya mengoptimalkan pertumbuhan dan perkembangan anak usia 0-6 tahun yang berada pada masa keemasan (golden age). Memperhatikan hal tersebut menjadi tugas utama orang dewasa yang dekat dengan anak untuk dapat memfasilitasi agar anak memiliki kesiapan dalam menghadapi tantangan di masa depan. Bentuk penyelenggaraan pendidikan anak usia dini menitikberatkan pada peletakan dasar ke arah pertumbuhan dan perkembangan fisik (koordinasi motorik halus dan kasar), 
intelektual, kecerdasan kognitif atau kecerdasan merupakan suatu proses mental sehingga tidak hanya sekedar kemampuan yang terkait dengan hal akademis (Mufarizuddin, 2017).

Salah satu kemampuan yang penting untuk dimiliki oleh anak usia dini adalah pemahaman tentang konsep aljabar. Pembelajaran aljabar penting untuk distimulasi pada anak usia dini sebelum anak dihadapkan pada persoalan aljabar di pendidikan selanjutnya. Stimulasi aljabar yang diberikan pada anak usia dini akan memberikan kesiapan pada anak untuk memahami dasar-dasar konsep aljabar yang diantaranya mencocokkan dan menyortir, pola, korelasi dan fungsi antara dan perubahan kualitatif dan kuantitatif. Oleh karena itu berikut ini disajikan hasil yang diperoleh berkaitan dengan penerapan aljabar pada anak usia 5-6 tahun.

Subjek penelitian berdasar hasil angket yang telah disebarluaskan, diperoleh karakteristik subjek yang telah dijabarkan pada Tabel 1.

Tabel 1. Data partisipan

\begin{tabular}{lcc}
\hline \multicolumn{1}{c}{ Kriteria } & Jumlah \\
\hline Usia & $21-30$ & 6 \\
& $31-40$ & 12 \\
& $41-50$ & 9 \\
Lama Mengajar & $51-60$ & 5 \\
& $1-10$ & 14 \\
& $11-20$ & 14 \\
Pendidikan Terakhir & $21-30$ & 3 \\
& $31-40$ & 1 \\
& D3 & 2 \\
& S1 & 24 \\
\hline
\end{tabular}

Data partisipan menunjukkan bahwa sebagian besar guru merupakan tenaga pendidik yang memiliki pengalaman mengajar yang cukup lama, 14 tahun pengalaman mengajar yang merupakan gambaran bahwa guru memiliki cukup banyak pengalaman dalam proses kegiatan belajar mengajar pada sutuan PAUD. Serta merupakan individu yang berada dalam kelompok usia produktif dan matang secara emosional dan mental. Sebagian besar guru telah memenuhi kualifikasi sebagai pendidik PAUD hal ini dapat dilihat dari hasil data di mana sebanyak 24 orang guru merupakan lulusan S1 hal ini menunjukkan bahwa guru cukup memiliki dan terbekali dengan pengetahuan terkait kompetensi guru yang diperoleh selama masa perkuliahan.

\section{Deskripsi implementasi materi Aljabar}

Perolehan data terkait dengan implementasi aljabar pada tingkat TK di kabupaten Magelang diperoleh hasil sebanyak 50\% dikategorikan cukup, sebanyak 46,9\% dikategorikan baik dan sisanya rendah. Implementasi pembelajaran aljabar di TK yang muatannya terdiri dari mencocokkan dan menyortir, pola, korelasi dan fungsi antara, serta perubahan kuantitatif dan kualitatif dapat dikatakan belum sepenuhnya diajarkan pada anak usia TK (5-6 tahun).

Tabel 2. Data Implementasi Aljabar

\begin{tabular}{lccc}
\hline Interval & Frekuensi & Persentase (\%) & Kriteria \\
\hline $30-36$ & 0 & 0 & sangat baik \\
$23-29$ & 15 & 46,9 & baik \\
$16-22$ & 16 & 50 & cukup \\
$9-15$ & 1 & 3,1 & rendah \\
\hline Jumlah & 32 & 100 & \\
\hline
\end{tabular}


Implementasi materi aljabar yang dilakukan oleh guru menunjukkan bahwa guru memiliki pemahaman dan penguasaan materi aljabar yang cukup baik. Hal ini dipahami guru untuk memberikan fondasi pengetahuan matematika melalui pembelajaran yang bersifat praktis, informal (melalui bermain) sebagai bekal dan dasar konsep matematika yang kuat di jenjang pendidikan selanjutnya yang tidak hanya terfokus pada penguasaan angka dan hitungan (Suryaningrum et al., 2021). Sejalan dengan hal ini dalam Peraturan Menteri Pendidikan Dan Kebudayaan Republik Indonesia Nomor 137 Tahun 2014 Tentang Standar Nasional Pendidikan Anak Usia Dini Pasal 10 dalam lingkup perkembangan kognitif disebutkan bahwa anak-anak perlu: a. belajar dan pemecahan masalah, mencakup kemampuan memecahkan masalah sederhana dalam kehidupan sehari-hari dengan cara fleksibel dan diterima sosial serta menerapkan pengetahuan atau pengalaman dalam konteks yang baru; b. berfikir logis, mencakup berbagai perbedaan, klasifikasi, pola, berinisiatif, berencana, dan mengenal sebab-akibat; dan c. berfikir simbolik, mencakup kemampuan mengenal, menyebutkan, dan menggunakan konsep bilangan, mengenal huruf, serta mampu merepresentasikan berbagai benda dan imajinasinya dalam bentuk gambar. Sehingga, dapat dipahami bahwa guru telah cukup memahami cakupan kompetesi yang perlu dikuasi anak.

Data implementasi materi aljabar yang telah diperoleh menjadi dasar untuk melakukan pengumpulan data lanjutan terkait materi aljabar apa saja yang diajarkan dan tidak diajarkan oleh guru serta faktor penghambat yang dialami guru.

\section{Frekuensi penerapan materi aljabar}

Hasil implementasi aljabar yang diterapkan oleh guru diperkuat dengan data frekuensi muatan aljabar yang dapat dilihat pada tabel 3. Data penelitian diperoleh nilai $62,5 \%$ guru paling sering melakukan kegiatan mencocokkan dan menyortir, hal ini ditegaskan juga dengan hasil nilai implementasi yang tinggi pada muatan aljabar tersebut sebesar 53,1\% sebagai muatan yang paling mudah diajarkan. Data lain yang diperoleh berupa muatan aljabar yang paling jarang sebesar 43,8\%, paling sulit 59,1\% bahkan belum pernah $81,3 \%$ diimplementasikan adalah muatan perubahan kualitatif dan kuantitatif.

Tabel 3. Data Frekuensi materi aljabar

\begin{tabular}{lccccc}
\hline Materi & $\begin{array}{l}\text { Sering } \\
(\%)\end{array}$ & $\begin{array}{l}\text { Jarang } \\
(\%)\end{array}$ & $\begin{array}{l}\text { Belum Pernah } \\
(\%)\end{array}$ & $\begin{array}{l}\text { Paling } \\
\text { mudah (\%) }\end{array}$ & $\begin{array}{l}\text { Paling } \\
\text { sulit (\%) }\end{array}$ \\
\hline $\begin{array}{l}\text { Mencocokkan dan } \\
\text { menyortir }\end{array}$ & 62,5 & 9,4 & 0 & 53,1 & 3,1 \\
$\begin{array}{l}\text { Pola } \\
\begin{array}{l}\text { Korelasi (hubungan) } \\
\text { dan fungsi antara }\end{array}\end{array}$ & 18,8 & 15,6 & 6,3 & 34,4 & 9,4 \\
$\begin{array}{l}\text { Perubahan kualitatif dan } \\
\text { kuantitatif }\end{array}$ & 6,3 & 31,3 & 12,5 & 6,25 & 28,1 \\
\hline
\end{tabular}

Berdasar data yang diperoleh terlihat bahwa meski guru telah cukup baik dalam mengimplementasikan pembelajaran aljabar namun guru belum sepenuhnya menguasai dan memahami seluruh materi aljabar yang perlu diajarkan kepada anak, sehingga tidak jarang dalam prosesnya kegiatan pembelajaran kurang beragam dan hanya berupa pengulangan kegiatan dengan materi tertentu saja. Hasil tersebut bertentangan dengan penelitian sebelumnya di mana dikemukakan bahwa anak-anak mempelajarai aljabar pada saat mengerjakan klasifikasi, pola, dan hubungan serta saat menjelajahi berbagai fungsi dengan atau tanpa symbol dan angka matematika (Lee et al., 2016), dengan kata lain aljabar tidak hanya terbatas pada salah satu materi saja namun merupakan materi berfikir menyeluruh yang menjadi tujuan utama dalam pembelajaran matematika pada anak usia dini yaitu untuk menumbuhkan disposisi produktif (termasuk rasa ingin tahu, imajinasi, penemuan, pengambilan resiko, kreativitas dan ketekunan) dan mendorong anak-anak untuk mampu 
berfikir matematis (J. A. Sarama \& Clements, 2009). Guru perlu meluaskan dan senantiasa memperbaharui wawasan dan pengetahuan terkait materi yang pelru diajarkan kepada anak. Guru perlu melakukan pengembangan diri yang berfokus pada pengetahuan konten atau materi pengetahuan khusus, tidak umum dan senantiasa berkaitan dengan anak agar dapat mengoptimalisasi perkembangan anak (Brendefur et al., 2013).

\section{Faktor penghambat implementasi materi aljabar}

Faktor penghambat diperoleh dengan melakukan pengambilan data lanjutan. Diperoleh data kendala yang dihadapi guru dalam mengimplementasikan aljabar diantaranya sebanyak $62,5 \%$ guru mengungkapkan faktor waktu yang terbatas dalam kegiatan belajar menjadi penghambat utama. Selanjutnya diikuti dengan minimnya buku panduan sebanyak $50 \%$ dan 46,9\% berpendapat kurangnya informasi yang diperoleh guru tentang muatan aljabar juga menjadi kendala bagi guru. Hal tersebut dapat diamati pada tabel 4 .

Tabel 4. Kendala yang dihadapi guru dalam mengimplementasi materi Aljabar

\begin{tabular}{lcc}
\hline Kendala & Frekuensi & Persentase (\%) \\
\hline minimnya buku panduan & 16 & 50 \\
waktu yang terbatas & 20 & 62,5 \\
kurangnya informasi & 15 & 46,9 \\
anak kurang antusias & 11 & 34,4 \\
\hline
\end{tabular}

Pada paparan data hasil penelitian yang peneliti peroleh dapat dipahami bahwa secara umum guru telah cukup menguasai materi aljabar, namun dalam implementasinya masih terbatas pada sebagain materi dari keseluruhan materi aljabar yang perlu diajarkan. Pada prakteknya guru mengalami beberapa kendala diantaranya guru kurang mendapatkan dukungan dalam hal peningkatan kompetensi melalui penyediaan informasi terkini baik dalam bentuk teksbook maupun pelatihan maupun kegiatan lain. Kurangnya informasi dan minimnya buku panduan berkaitan dengan materi matematika secara spesifik yang diperoleh guru, sebagian besar guru hanya mengajar dengan berpegang pada apa yang tertulis di STPPA tanpa terlebih dahulu menelaah isi STPPA tersebut sehingga pembelajaran pun berlangsung secara umum dan sesuai dengan intrepretasi masing-masing guru.

Guru membutuhkan pengetahuan khusus dalam setiap materi pembelajaran agar mampu menyajikan pembelajaran yang lebih bermakna dan mendukung optimalisasi perkembangan anak. Oleh karena itu disarankan agar guru taman kanak-kanak untuk terus mengembangkan kompetensi dalam mengembangkan pembelajaran khususnya berkaitan dengan aljabar maka perlu untuk mengikuti berbagai program pelatihan atau diklat. Hal ini menjadi penting bagi guru karena dengan meningkatkan dukungan guru untuk mengembangkan proses pembelajaran matematika anak membutuhkan lebih dari sekedar menghadirkan kurikulum baru kepada guru (Takunyaci \& Takunyaci, 2014). Peran sekolah dalam memfasilitasi pengembangan pengetahuan pedagogis pendidik serta keterlibatan program sekolah sangat mempengaruhi perkembangan belajar matematika anak (Winitri et al., 2020).

\section{SIMPULAN}

Kemampuan penguasaan materi aljabar guru perlu ditingkatkan dengan mengadakan pelatihan yang dikemas khusus untuk membantu guru menguasai setiap konten materi aljabar serta menghindari pengulangan kegiatan pembelajaran. Penyediaan bahan referensi yang memadai membantu meningkatkan kompetensi guru untuk mencukupi pengetahuan anak serta mendukung perkembangan rasa ingin tahu anak dalam pemerolehan pengetahuan dan pengalaman baru anak. Guru perlu lebih memahami konsep pembelajaran terpadu sehingga setiap materi dapat terimplementasikan dengan lebih merata. 


\section{UCAPAN TERIMA KASIH}

Kami mengucapkan terimakasih kepada LPPM yang telah memberikan dukungan hingga terselesaikannya artikel ini. Selain itu kami juga mengucapkan terimakasih kepada dosen-dosen di PG PAUD Universitas Muhammadiyah Magelang serta guru-guru TK sekabupaten Magelang yang telah bersedia menjadi responden dalam penelitian ini.

\section{DAFTAR PUSTAKA}

Adjie, N., Putri, S. U., \& Dewi, F. (2020). Peningkatan Kemampuan Koneksi Matematika melalui Pendidikan Matematika Realistik (PMR) pada Anak Usia Dini. Jurnal Obsesi : Jurnal Pendidikan Anak Usia Dini, 5(2), 1325-1338. https:// doi.org/10.31004/obsesi.v5i2.846

Afonso, D., \& Auliffe, S. M. (2019). Children ' s Capacity for Algebraic Thinking in the Early Grades Children ' s Capacity for Algebraic Thinking in the Early Grades. 7295. https:// doi.org/10.1080/18117295.2019.1661661

Ball, D. L. (2003). RAND Corporation Chapter Title: CONCLUSIONS Book Title: Mathematical Proficiency for All Students: Toward a Strategic Research and Development Program in Mathematics Education Book Author ( $\mathrm{s}$ ): RAND Mathematics Study Panel and Deborah Loewenberg Ball.

Brandt, B. (2013). Everyday pedagogical practices in mathematical play situations in German "Kindergarten." Educational Studies in Mathematics, 84(2), 227-248. https:// doi.org/10.1007/s10649-013-9490-6

Brendefur, J., Strother, S., Thiede, K., Lane, C., \& Surges-Prokop, M. J. (2013). A Professional Development Program to Improve Math Skills Among Preschool Children in Head Start. Early Childhood Education Journal, 41(3), 187-195. https:// doi.org/10.1007/s10643-012-0543-8

Peraturan Menteri Pendidikan dan Kebudayaan Republik Indonesia Nomor 137 Tahun 2014 Tentang Standar Nasional Pendidikan Anak Usia Dini.

English, L. D. (2012). Data modelling with first-grade students. Educational Studies in Mathematics, 81(1), 15-30. https:// doi.org/10.1007/s10649-011-9377-3

Gardiner, A., Marum, T., Isler, I., Stephens, A., Knuth, E., \& Blanton, M. (2011). From Specific Value To Variable: Developing Students' Abilities To Represent Unknowns. Proceedings of the 33rd Annual Meeting of the North American Chapter of the International Group for the Psychology of Mathematics Education., October, 106-112.

Groves, R. M., Floyd J. Flower, J., Couper, M. P., Singer, E., \& Tourangeau, R. (2009). Survey Methodology. John Wiley \& Sons.

Heuvel-Panhuizen, M. van den, Elia, I., \& Robitzsch, A. (2016). Effects of reading picture books on kindergartners' mathematics performance. Educational Psychology, 36(2), 323-346. https:// doi.org/10.1080/01443410.2014.963029

Keller, B. A., Hart, E. W., \& Martin, W. G. (2001). Illuminating NCTM's Principles and Standards for School Mathematics . School Science and Mathematics, 101(6), 292-304. https:// doi.org/10.1111/j.1949-8594.2001.tb17960.x

Kirkland, L. D., Manning, M., Osaki, K., \& Hicks, D. (2015). Increasing logico-mathematical thinking in low SES preschoolers. Journal of Research in Childhood Education, 29(3), 275-286. https:// doi.org/10.1080/02568543.2015.1040901

Lee, J., Collins, D., \& Melton, J. (2016). What Does Algebra Look Like in Early Childhood? Childhood Education, 92(4), 305-310. https:// doi.org/10.1080/00094056.2016.1208009

Li, X. (2020). Investigating U.S. Preschool Teachers' Math Teaching Knowledge in Counting and Numbers. Early Education and Development, 00(00), 1-19. https://doi.org/10.1080/10409289.2020.1785226

Matin, \& Fuad, N. (2016). Manajemen Sarana Dan Prasarana Pendidikan Konsep dan Aplikasinya (Ed.1. Cet,). Rajawali Pers. https://doi.org/10.17977/um025v1i12016p060 
Misrawati, M., \& Suryana, D. (2021). Bahan Ajar Matematika Berbasis Model Pembelajaran Tematik terhadap Kemampuan Berhitung Anak Usia Dini. Jurnal Obsesi: Jurnal Pendidikan Anak Usia Dini, 6(1), 298-306. https:/ / doi.org/10.31004/obsesi.v6i1.1249

Mufarizuddin, M. (2017). Peningkatan Kecerdasaan Logika Matematika Anak melalui Bermain Kartu Angka Kelompok B di TK Pembina Bangkinang Kota. Jurnal Obsesi : Jurnal Pendidikan Anak Usia Dini, 1(1), 62. https:// doi.org/10.31004/obsesi.v1i1.32

Nunes, T., Bryant, P., \& Watson, A. (2009). Key Understandings in Mathematics Learning: Methodological Appendix. In The Scottish Mathematical Council Journal (Vol. 40). https://mk0nuffieldfounpg9ee.kinstacdn.com/wpcontent/uploads/2019/11/SMC_Watson.pdf

Papandreou, M., \& Tsiouli, M. (2020). Noticing and understanding children's everyday mathematics during play in early childhood classrooms. International Journal of Early Years Education, 0(0), 1-18. https://doi.org/10.1080/09669760.2020.1742673

Papic, M. M., Mulligan, J. T., \& Mitchelmore, M. C. (2011). Assessing the development of preschoolers' mathematical patterning. Journal for Research in Mathematics Education, 42(3), 237-268. https:// doi.org/10.5951/jresematheduc.42.3.0237

Rusdiana, A., \& Sudirman, S. (2016). Berpikir secara Aljabar pada Anak Pra Sekolah. April, 08.

Rutunkahu, J. T., \& Kandou, S. (2017). Pembelajaran Maematika bagi Anak Berkesulitan Belajar (2nd ed.). Ar-Ruzz Media.

Sarama, J. A., \& Clements, D. H. (2009). Early childhood mathematics education research: Learning trajectories for young children. In Early Childhood Mathematics Education Research: Learning Trajectories for Young Children. https://doi.org/10.4324/9780203883785

Sarama, J., \& Clements, D. H. (2010). Preschool mathematics curricula. Mathematics Curriculum

Issues, Trends, and Future Direction, October 2016, 115-126.

Suryani, N. A., \& Haryono, M. (2018). Improvement of the Logical Intelligence Through Media Kolak (Collage Numbers) Based on Local Wisdom on Early Childhood. Jurnal Obsesi : Jurnal Pendidikan Anak Usia Dini, 2(2), 253. https:// doi.org/10.31004/obsesi.v2i2.90

Suryaningrum, C. W., Misyana, M., \& Jatmikowati, T. E. (2021). Playing Mathematics in Early Childhood Based on Semiotics. Jurnal Obsesi : Jurnal Pendidikan Anak Usia Dini, 6(2), 601-610. https://doi.org/10.31004/obsesi.v6i2.1341

Takunyaci, M., \& Takunyaci, M. (2014). Preschool Teachers' Mathematics Teaching Efficacy Belief. Procedia - Social and Behavioral Sciences, 152, 673-678. https://doi.org/10.1016/j.sbspro.2014.09.261

Tohir, M. (2019). Hasil PISA Indonesia Tahun 2018 Turun Dibanding Tahun 2015. https://doi.org/10.31219/osf.io/pcjvx

Winitri, R., Hapidin, H., \& Nurani, Y. (2020). Perbedaan Hasil Belajar Matematika Anak Usia 6-7 Tahun ditinjau dari Pemahaman Guru pada Pembelajaran Transisi dan Regulasi Diri. Jurnal Obsesi : Jurnal Pendidikan Anak Usia Dini, 4(2), 491. https://doi.org/10.31004/obsesi.v4i2.402 